\title{
Historical Changes in Modeling Language Features of Henan Yuzhou Jun Porcelain
}

\author{
Haihong Xie \\ Eastern International Art College \\ Zhengzhou University of Light Industry \\ Zhengzhou, China
}

\begin{abstract}
Starting from modeling language features of Henan Yuzhou Jun Porcelain, the thesis tries to give a comparative research on Jun Porcelain's model, color, texture and so on. Furthermore, as for Jun Porcelain's historical status, artistic value, aesthetic value, manufacturing technique, time feature, development trend and so on, the thesis makes a contrast with other porcelains and then makes a summary on modeling language features and rules of Henan Yuzhou Jun Porcelain, which will play an active role in enriching modeling language of Jun Porcelain, perfecting local modeling art design and improving the ability of aesthetic appreciation.
\end{abstract}

Keywords-Jun Porcelain; modeling language; furnace transmutation; texture; color

\section{HISTORICAL STATUS AND TIME FEATURE OF HENAN YUZHOU JUN PORCELAIN}

As one of the five ancient famous major kilns in Song Dynasty, Jun Porcelain has a history of more than 1300 years. It was born in last years of Tang Dynasty, reached the best developing period of Song Dynasty. As the birthplace is Yuzhou, it's researched that it was named after Qi, King of Xia Dynasty, held founding ceremony at Jun Platform. With time going on, especially after Song Dynasty, the culture became abundant and spirit required improving. In addition, with constant improvement and innovation of modeling and firing technology, Jun Porcelain became one of the essential parts of ceramic art.

The glazing formula of Jun Porcelain based on iron oxide completely changes the traditional way of using simple celadon, making the structure of glaze layer more complicated. With the effect of light, the glaze layers become colorful just like the gem out of water. In addition, with the controlling function to the light when people appreciate the glaze layers, glazing colors will be much more abundant and beautiful, which will further strengthen the artistic charm of Jun Porcelain. Whether from modeling to glazing changes or from texture pictures to hacking lines "Fig. 1", Henan Yuzhou Jun Porcelain is incomparable to other kinds of porcelain. It's deserved to be entitled the treasure of Chinese traditional ethnic culture.

With the development and changes for hundreds of years, experiencing suffering and troubles, it is not easy to be continued till now. In the process, many people made great contributions and much sacrifice. Since the founding of new
China, with the support and care from our party, it has been turned a new look to the world. The present Jun Porcelain is good in modeling design and firing technique. After a long history of its development and innovation, the production of Jun Porcelain are approaching perfect in art style and glazing techniques.

As the representative of the culture in north China, Henan Yuzhou Jun Porcelain has the rough and bold modeling, natural and interesting pictures, simple and elegant colors. Comparing to porcelains in south China, from aesthetic view, it has vivid characters with grand, simple, imaginary, personality and tactful beauty.

On the whole, colorful glaze is the striking feature of Henan Yuzhou Jun Porcelain in Tang Dynasty, when the main porcelain was used as daily necessities and the modeling of this time was so plump and soft. According to aesthetic needs, the modeling of Henan Yuzhou Jun Porcelain was developed to graveness and grandness.

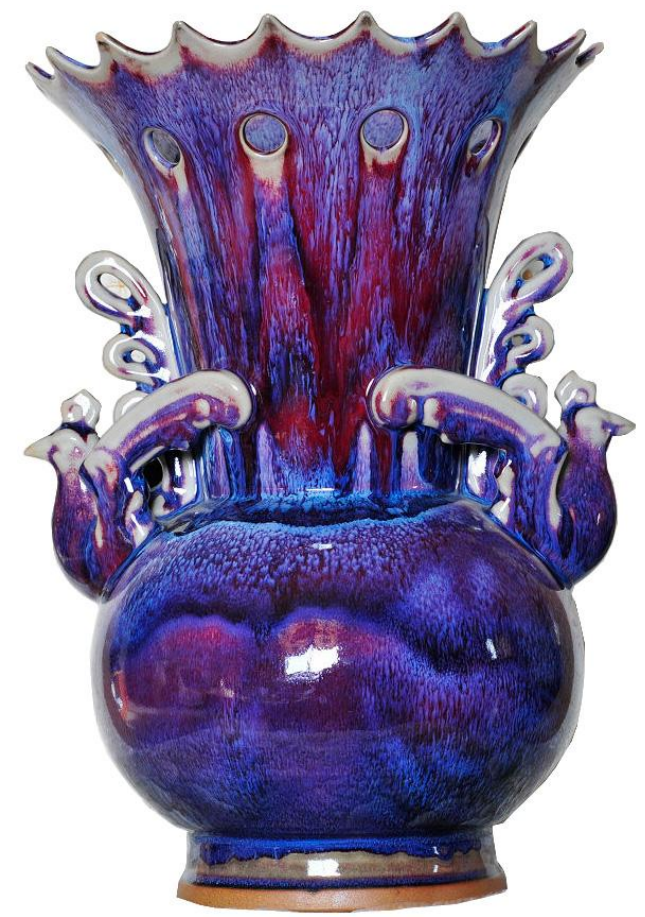

Fig. 1. Glaze changes of Jun Porcelain. 
Reflected abundant cultural connotation and profound humanism atmosphere, Henan Yuzhou Jun Porcelain in Song Dynasty were neither lovely and artificial nor natural and facetious. However, enjoying the changeable glazing colors of Jun Porcelain, which is simple and plain, we feel it's elegant indeed. Due to its elegant modeling, which reflected natural charms, Jun Porcelain in Song Dynasty was considered as the representative of elegance by Jun Porcelain aestheticians "Fig. 2".

Comparing with Jun Porcelain in Song and Jin Dynasties, Yuan Dynasty is a good period for further development of Henan Yuzhou Jun Porcelain, which is produced mainly for big and heavy products. The common features are: rough glaze, simple technique, uneven glaze thickness, candle-like glaze thickness, artificial sceneries, etc. Comparing with Yuzhou Jun Porcelain in Song Dynasty, it was not so pretty.

Because of war and other disasters, there are only a few good Jun Porcelains in Ming Dynasty. From the existing Jun Porcelains of Ming Dynasty, it was popular in the periods of Hongwu, Yongle and Xuande. From then on, due to political turbulence, Jun Porcelain seemed to decline. In the period of Jiajing, despite the whole-hearted support of Emperor Shizong (Zhu Houcong), Jun Porcelain still couldn't be restored to normal state. Jun Porcelain of this period tended to elegant modeling, gorgeous glazing, pearly texture and neat technique, so descendants addressed this style of Ming Dynasty as "gorgeous".

On the basis of inheritance of traditional technique, Henan Yuzhou Jun Porcelain in Qing Dynasty turned to make a breakthrough of glazing materials. With the influence of north and south culture, Jun Porcelain gradually improved rough and bold modeling, therefore the simple and elegant glaze turn on an elegant look.

Experienced the restoration period in the 1950s, the enlightenment period in the $1960 \mathrm{~s}$, the development period in the 970s, it reached the mature period in the 1980s. In October, 1983, Jun Porcelain of Shenhou town was exhibited at National Art Museum of China in Beijing, which indicated that Chinese Jun Porcelain is approaching perfect and mature.

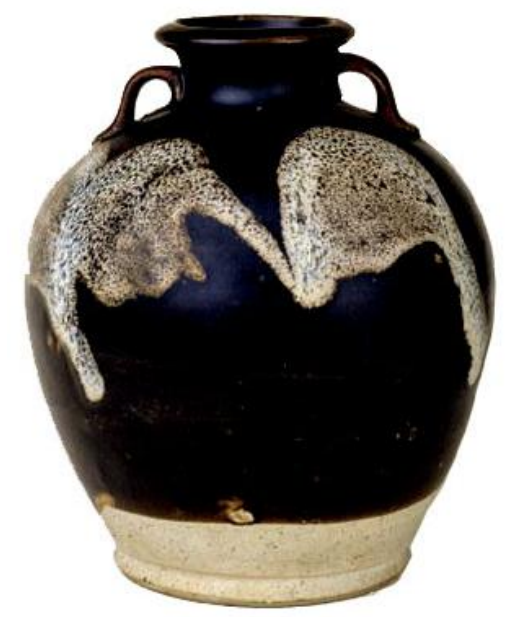

Fig. 2. Yuzhou Jun Porcelain, Tang Double Tank

\section{II. "ForM" FEATURE IN MODELING LANGUAGE OF HENAN YUZHOU JUN PORCELAIN}

The Yuzhou Jun porcelain is the representative of the northern culture, charming with rustic style, elegance in drawing, and dignity in painting. "Form as the essence and glaze as the soul" is the highly generalization of the Henan Yuzhou porcelain arts. It can be divided into traditional and modern Jun porcelain, according to the difference of the characteristics of the times, of Jun porcelain's modeling.

The traditional Jun porcelain's modeling is based on the daily use household utensils, such as flower pots, receptacles, plates, pots, bowls and cups. In the production design, practicability is in a prominent position, appearance a subordinate position, with the main pursuit of naturally artistic style. The less utility of utensils such as bottles, pot, furnace, is mainly used in treasure play and ancestor worship, with the valuable orientation of meeting the demand of noble royal life. Modeling design mostly adopts the bodiless and bronze ware's shape, simple and generous, with the pursuit of quality and style, based on the vigorously dignified shape; simplicity and elegance artistic features. The utensil fully embodies the traditional aesthetic intention of China, with clear ware angular, graceful lines, appropriate and harmonious contrast, moreover mainly in symmetry. As far as Jun porcelain industry is concerned which is in deeply tradition, it simply means the past glory and unique cultural sedimentation, but to the later generations, it may be a massive wealth and fertile soil, may also be a heavy historical burden. In such a cultural heritage that our forebears leave, how to protect and inherit, has a special significance in the present.

Modern Jun porcelain is created by ceramic artists, professors from Fine Arts Academy, according to their ideas and awareness, full of the flavor of the times and personal style. These works break the traditional concepts and practices, "to use of contemporary aesthetic ideas and passionate style of art creating the works of breaking the traditional concept ", notably Han Meilin's and Zhou Guozhen's works and so on. Mr. Han thinks that excellent traditional cultures should be inherited, putting the traditional Chinese art's beauty into the Jun's creation by studying Jun porcelain, expressing his own unique views. His modern ceramic series of works are the traditional and modern aesthetic concept of harmony. Jun porcelain modeling should has the leading and showing concept in design, which makes Jun porcelain, this nation's traditionally outstanding culture and art keep pace with the times, and improve quality constantly. His masterpiece is "Merrill Lynch Fish". In this work, he puts the western oil painting techniques and Chinese traditional ceramic art into effective combination, to create Jun porcelain works unprecedentedly. It is not unique, but has its counterpart, that master Kong Xiangqing who is famous for its traditional modeling process, designed many new concise and beautiful shapes in smooth lines, combined with the need of modern people, such as general bottle, uniform bottle, Ruyi bottle while summing up novels about historical events. Meanwhile, he enriched the forms of Jun porcelain, combined with modern artistic techniques of sculpture and stenciled design. He created a lot of works in 
the flavor of the new times with the modern concept, greatly expanding the developing space of Jun porcelain. His innovation has caused widespread influence in the porcelain industry. The 'Hai Yan Pot "is a representative work of sacrificial vessel series, which was chosen as the gift of China - ASEAN Expo country in the fourth session, presented to the leaders of ASEAN leaders on October 12, 2010.

The figures in the traditional modeling are created by Jun porcelain artists "Fig. 3", according to the legend, historical allusions or related story characters. This kind of theme is about fairy in majority. Traditional Jun porcelain modeling is not enough for facial expressions and refinement, while modern artists are very focused on details of the carved face. They often portray the character, animal expressions and body actions meticulously; therefore modeling has the romantic charm. A not very high seated figure of Guanyin, is portrayed meticulously based on traditional modeling through eye, eyebrow, lip and so on, more than 30 complex processed, depicting a vivid expression, likeness of a true Guanyin image. At the same time, with paste approach double lotus petals are produced. Pieces of petals bloom slimly and gracefully, which win people's great admiration.

Jun porcelain art has achieved the excellent results; however it still has the imperfect side. With the increasing number of Jun porcelain modeling, there are some problems. For example, some simple forms pile up the traditional cultural symbols; some modeling overemphasized the meaning, unrestrainedly combining sculpture with earrings to render some themes which have shallow understanding. These problems have caused people with breadth of vision to dispute and worry about.

The Design of Jun porcelain modeling is not only to reflect the aesthetic appearance, but also has a great impact on forming of Jun porcelain and glaze color effect of furnace transmutation. Jun porcelain is the ingenious combination of modeling beauty and glaze of beauty. The traditional class of Jun porcelain mainly take the round modeling as basic, mostly to comply with the modeling principle of "short legs and upper body, big belly", consistent with the human body proportion, showing a harmonious golden ratio. Jun porcelain modeling exquisite symmetrical relationship of great decent shape and work in concert with the upper and lower in the part of "neck, body and foot", reflecting the ancient tradition of the aesthetic principle; with the pursuit of natural change or more decent organic combination, of unique of ensemble, considering the integrity and unity of details, reflecting the form the beauty of symmetry and balance, the static and dynamic combination.

\section{COlOUR FEATURE IN MODELING LANGUAGE OF HENAN YUZHOU JUN PORCELAIN}

Named as one of the major five treasureable kilns in China, Henan Yuzhou Jun Porcelain contributed mainly to the firing gorgeous Jun Porcelain with red glaze. Since then, it is been the start of copper red glaze and changed the condition that only black and blue glazes can be produced in high temperature, which opens up a new level of art.

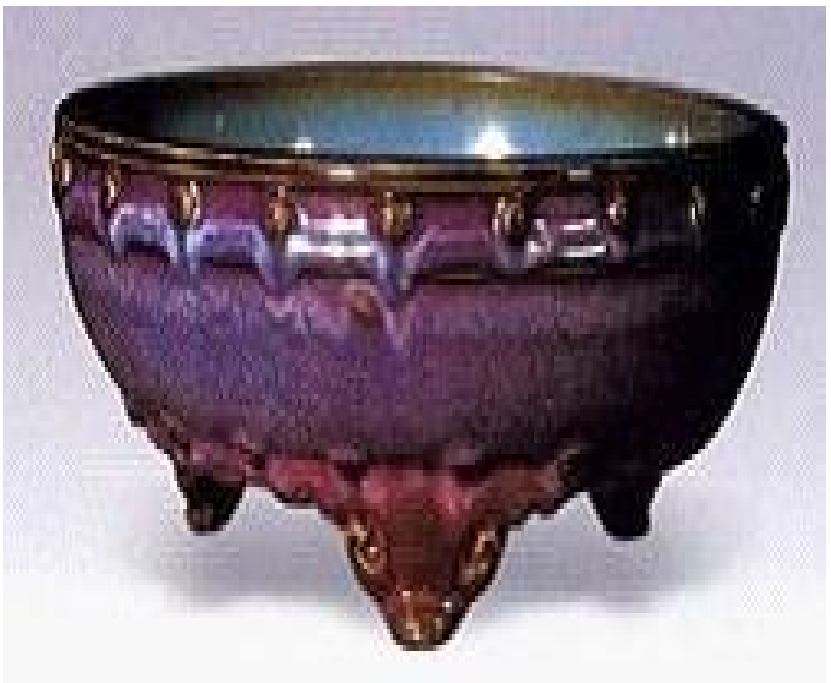

Fig. 3. Traditional Classic Modeling

Color changes mainly relies on natural furnace transmutation, which is the essence of Jun Porcelain art. The furnace transmutation of Jun Porcelain is varied in colorful and graceful postures and usually it is shown as a mixture of colors, which is blue with red, red with purple, green with white, connecting with each other and reflecting gorgeous light. Jun Porcelain is the art of fire. Before firing, the base has no color. However, after firing, it is colorful. Therefore, a wise saying comes, "Base with one color in kiln and then colorful porcelain will be out". The effect of changeable furnace transmutation is the root and soul of Jun Porcelain and of course, the process of this technique has a long history.

Before Tang Dynasty, the production of porcelain mainly is based on celadon. In Tang Dynasty, with the rapid development of porcelain, the colors of glazing materials are not the simple celadon but varying to diversification. Later, what appeared in succession was the main technique of porcelain making based on under glaze color and tri-colored glazed pottery and so on. In North Song Dynasty, on the basis of blue-and-white porcelain technique, the craftsman added a little microelement like copper and fired it to copper red glaze by oxidation-reduction method. In this way, Jun Porcelain improved and broke through in technique with the colors of furnace transmutation such as rose violet, Chinese flowering crabapple red and so on.

In modern times, the glaze color of furnace transmutation has been developed a lot. On the basis of the inheritance of tradition, the craftsman focused on the breakthrough of glazing colors. They glazed separately with the elements like copper, iron, phosphor, tin and so on. Layer by layer, the glazing structure of Jun Porcelain became complicated. With the effect of light, the glaze layers become colorful just like the gem out of water.

Yuzhou Jun Porcelain is the only flow glaze among Chinese porcelains. With the furnace transmutation making the flowing marks vivid at high temperatures, Jun Porcelain presents gorgeous glazes. Of all the varieties, the most wonderful glazes are vermilion, carmine, Danxia red, crabapple red, lilac, rose violet, lily magnolia purple,, grape 
purple, azure, plum azure, bluish white, etc. More amazingly, after the furnace transmutation, the glazing materials of Jun Porcelain are shown series of pictures. The splendid works makes people connect feelings and settings, which bring people to a dim and abstract atmosphere of art. Furthermore, with the effect of light in the process of appreciation on the glaze layers, the glaze colors become colorful and beautiful just like stars and clouds, which make Jun Porcelain much more charming.

Due to the furnace transmutation, Yuzhou Jun Porcelain becomes colorful. However, the process of coloring demands a lot and it's hard to reach certain level. So it is hard to fire good-looking porcelain. During the firing, if fire fails, the game of producing good porcelain will be over. The colors of furnace transmutation matter much with materials, fuels, temperature, placing position of base and so on. Moreover, it also connects with the climate, so there is no similar Jun Porcelain in the world.

\section{TeXture Feature IN Modeling LANGUAGE OF HENAN YUZHOU JUN PORCELAIN}

The texture features of Jun Porcelain contains two aspects: glazed surface texture and glazed texture painting. Magical crackle phenomenon increased the mystery of Jun Porcelain, whose surface is like ice crack. Touching, it feels smooth. Presented in Taoism philosophy of natural formation, changes of glazed textures are like earthworm line, crab line, Chinese dodder line, pearl line, peacock feather line and fox fur line. It is simple and plain, we feel it's elegant indeed.

The most splendid texture is the appearance of scenery. With the furnace transmutation, glaze color, surface texture and colored spot are combined and formed a vivid picture just like humans, animals and series of landscape painting. Among the techniques, most famous is listed as "Evening mist and rosy clouds"," Jackdaw entering the forest"," Rain in south China" and so on. The technique is so bold and free. Conveying the meaning ahead of design, the pictures on the porcelain express in details or in simple words. Such simple surface textures and texture painting contain profound cultural connotation and humanism information. Different angle to see, you can see different pictures, which are gorgeous and simple. As for Jun Porcelain, people have various views. The artistic conception in pictures, which presents beauty of conception, is nothing but the conception pursued by traditional man of letters.

\section{CONCLUSION}

In the process of economic development, people come to realize that the development and revitalization of culture industry is the base of sustainable economic development. Therefore, it's common view to inherit the development of traditional culture and excellent traditional technique. The thesis analyzes the rule of Yuzhou Jun Porcelain's modeling language and color and explores cause and rule of color texture and glaze in furnace transmutation. It also makes a specification in classification of Jun Porcelain's modeling, colors and texture, and then summarizes how the elements of material, technique and aesthetics influence Jun Porcelain's modeling, colors and texture.
Through systematic research on traditional culture of Jun Porcelain, I hope it will be helpful to improve and strengthen inner driving force of traditional Jun Porcelain culture and provide the support to sustainable development of Jun Porcelain industry.

\section{REFERENCES}

[1] Chen Jinhai. World Ceramics Art History [M]. Harbin: Heilongjiang Fine Arts Publishing House, 1995.

[2] Chen Wanli. Chen Wanli Ceramics Archaeology Essay ( 2nd version) [M].Beijing: Zijincheng Publishing House, 1997.

[3] Fu Zhenlun. Chinese Ancient Ceramics Essay [M]. Beijing: China Radio and TV Publishing House, 1994.

[4] Cao Jianwen. History of National Treasure (Ceramics) [M].Nanchang Jiangxi Fine Arts Publishing House, 2008.

[5] Zhu Shunlong. Li Jianjun. Ceramics and Chinese Culture [M] Shanghai: Chinese Great Dictionary Publishing House, 2003.

[6] Ministry of Light Industry Ceramic Industry Scientific Research Institute. Chinese Ceramics (revised version) [M].Beijing: Ministry of Light Industry Publishing House, 1983.

[7] Jin Peizhang. Chinese Ceramics Art [M].Zhengzhou: Henan People's Publishing House, 2003.

[8] Li Zhengming. Go to the Root: Jun Porcelain [M].Zhengzhou: Henan People's Publishing House, 2003. 